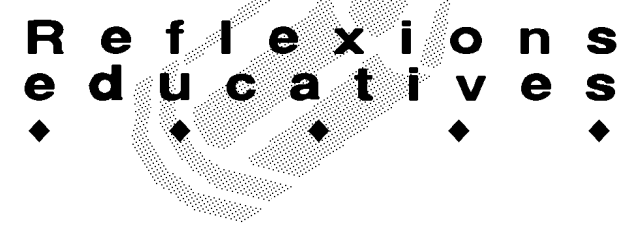

\title{
LA "COMPETÈNCIA" I ELS APRENENTATGES ESCOLARS: L'ÀREA DE MATEMÀTIQUES
}

\author{
Luisa Girondo Pérez. Àrea de Didàctica de la Matemàtica. URV
}

\section{La competència o les competències?}

El terme "competència", que prové del món professional amb una significació més o menys consensuada i clara (competències professionals), ha començat a utilitzar-se en el món educatiu amb significacions no del tot coincidents, i per tant, és recomanable que ens preguntem, davant de cada utilització, amb quin sentit s'empra el terme competència. Simone (GIRONDO, 2004) caracteritza la competència com la capacitat de fer front a demandes complexes i justifica la seva inclusió en el camp educatiu argumentant que per als ciutadans del futur no és suficient acumular coneixements i estar socialitzat, sinó que els ciutadans han d'aprendre a tenir posicions crítiques, a prendre decisions amb criteri, que ha de ser fruit de tenir un enfocament reflexiu davant les coses. Aquesta idea general va aterrant a les pràctiques educatives concretes, i així és suficient una ullada a diferents documents del camp educatiu actual per captar que el terme s'està utilitzant amb significats diferents.

Aquí ens limitarem a les significacions que s'observen en l'àmbit d'aquest article. La significació que ha donat, fins ara, el Departament d'Educació de la Generalitat de Catalunya a l'hora d'elaborar les competències bàsiques, i la significació del terme competència en elaboracions més pròpies del camp de l'educació matemàtica: fonaments teòrics de les proves PISA (www.oecd.org), estàndards curriculars, bibliografia de didàctica de la matemàtica, etc, i que ja es veuen reflectides en els currículums d'alguns països.

El terme competència, segons l'opció adoptada pel Departament d'Educació a l'elaborar les proves, denota un "saber fer", que es fonamenta en la utilització eficaç d'un conjunt de recursos que l'alumne ha adquirit i que mobilitza de manera efectiva davant d'un problema que ha de resoldre, o d'una situació determinada que també ha de resoldre. Es pot dir que es tracta d'una capacitat que ha d'incloure sabers i habilitats de tipus diferents (sabers disciplinaris, habilitats intel-lectuals, valors, trets de la personalitat...) que l'alumne ha de saber triar, combinar i posar en pràctica davant d'una situació complexa. Valorem que, en la seva formulació general, és una idea propera a la que es fa servir al parlar de competència professional. A la vista de les tasques concretes a realitzar per avaluar la competència bàsica, en el marc de la institució escolar, s'observa que es necessiten sabers disciplinaris i certes habilitats intel-lectuals, però no es distingeix tan clarament l'ús dels altres components (valors, trets de personalitat...).

En els fonaments teòrics d'educació matemàtica que serveixen de base per a l'elaboració de les proves PISA de matemàtiques, s'opta per denominar competència els processos cognitius complexos que els alumnes han d'utilitzar per realitzar una tasca de caire matemàtic. Concretament, es defineixen vuit competències: Pensar i raonar matemàticament, argumentar, comunicar, modelar, plantejar i resoldre problemes, representar, utilitzar el llenguatge simbòlic, formal i tècnic de les operacions, i utilitzar suports i eines. Moltes d'aquestes competències es poden veure com els processos intel.lectuals que acompanyen l'activitat matematitzant -o matemàtica- que els alumnes han de fer amb una finalitat determinada. L'activitat en si seria la de resoldre problemes.

En alguna bibliografia de Didàctica de la Matemàtica s'intenta caracteritzar la "competència matemàtica", aqueIla que es pretén que els alumnes assoleixin durant l'escolaritat, a través dels diferents aspectes, tant de caire conceptual com de processos. Un exemple el podem trobar a Linares (2003), on es diu que per arribar a ser matemàticament competent cal: comprensió conceptual; desenvolupament de destreses procedimentals; pensament estratègic (formular, representar i resoldre problemes); capacitats de comunicar i explicar matemàticament i actituds positives de l'alumne en relació amb les seves pròpies capacitats per fer matemàtiques.

Si s'aprofundeix una mica, es veu que no hi ha contradicció entre els diferents usos del terme aquí descrits, malgrat la no coincidència. Aquest aspecte es visualitza millor si es consideren les tasques que proposen per avaluar la cultura matemàtica (PISA) o la competència bàsica (Departament d'Educació). No obstant això, sí que es pot dir que tant el plantejament de PISA com la bibliografia específica citada expliciten les habilitats o processos necessaris per implicar-se en tasques matemàtiques, descripció que valorem útil de cara al treball de matemàtiques a l'escola. Les reflexions que a 


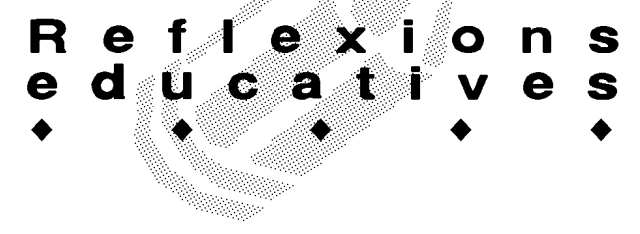

continuació s'exposen accentuen les coincidències de les formulacions.

- Per competència s'entén una capacitat d'acció, que no és una simple aplicació sinó que va més enllà.

- La competència és una mena de capacitat que no admet una anàlisi simple de processos psicològics, ja que hi influeixen molts aspectes.

- Es veu la competència en la capacitat de realització d'una tasca de certa complexitat.

- La competència admet diferents graus, des de nivells molt baixos de competència a nivells alts, tot i que és difícil pensar que hi hagi un límit superior de nivell de competència.

- Es poden pensar tasques per avaluar el nivell de competència.

\section{Currículums i competències}

La psicologia cognitiva parla de l'acció com a motor del pensament, de les capacitats lògiques dels alumnes en edats escolars, de les habilitats psicològiques necessàries... Les investigacions en educació matemàtica aporten nombroses dades de l'aprenentatge significatiu dels tòpics de la disciplina i recomanen pràctiques didàctiques adients. I la política educativa, preocupada per donar al ciutadà el necessari per inserir-se socialment $i$ progressar, va posant fites cada vegada més exigents i/o més completes.

En aquesta línia, molts currículums de països avançats ara defineixen els seus objectius escolars en termes de competències. Indiscutiblement, fixar objectius en termes de competències és acceptar, per part de l'escola, la responsabilitat del desenvolupament cognitiu dels alumnes. Els joves d'avui en dia, immersos en un medi culturalment molt ric, reben informacions de fonts diverses, però l'escola s'ha d'ocupar d'ajudar-los a triar, a decidir, a veure el que és important i el que no ho és; a vetllar per l'adquisició d'instruments i habilitats necessaris per a la vida en una societat que cada cop és més complexa. Són aquestes necessitats les que, en el moment actual, porten a parlar de desenvolupar competències i a no conformar-se amb l'adquisició de certs sabers que, tot i ser necessaris, es valoren com a insuficients. Portar la idea de competència als currículums implica, doncs, una voluntat d'iniciar, des de l'escola, el desenvolupament d'habilitats complexes que seran esssencials per a l'adaptació posterior de l'individu a un ambient canviant que requereix eines intel-lectuals flexibles. Eines que han de ser adequades per ajustar-se a les transformacions i per afavorir l'adquisició de nous coneixements.

Presentar l'àmbit matemàtic a l'educació primària sota el perfil de la competència implicarà, doncs, preo- cupar-se pel desenvolupament de "processos", alhora que s'adquireixen comprensivament certs conceptes i procediments propis de la disciplina per ser utilitzats de manera flexible i convenient. La matemàtica escolar ja no es pot entendre com el conjunt de sabers culturalment organitzats i que es poden trobar en un llibre, sinó que cal considerar la mateixa activitat matemàtica que l'alumne ha de posar en joc. És una activitat intel-lectual que cada alumne realitzarà al tractar de resoldre determinades qüestions o de donar sentit a fenòmens que s'observen.

La necessitat d'atendre tots els alumnes, de procurar que cada un desenvolupi al màxim les seves potencialitats, no ha de fer-nos esperar una uniformitat en les fites assolides. Per tant, és una decisió de la política educativa fixar uns mínims que contemplin allò que és més bàsic. Més bàsic en el sentit de més necessari per a la vida personal, per a la vida en societat i per a la pràctica professional. $O$ més bàsic per continuar aprenent si som als nivells d'educació primària. En el llenguatge competencial, cal acceptar un desenvolupament continu: en un extrem del segment se situaria un baix nivell de competència i a l'altre un nivell alt, passant per diferents graus que poden representar diferents moments de la vida escolar d'un alumne.

\section{Els objectius de la matemàtica escolar}

La idea tradicional de considerar la matemàtica escolar amb el doble objectiu de formativa i d'instrumental continua sent vàlida. Ningú no dubta que els futurs ciutadans tenen la necessitat d'utilitzar -amb certa fluïdesa- els llenguatges que la societat fa servir per descriure, actuar i predir el món físic, social i cultural que els envolta. És en aquest aspecte que la matemàtica juga un paper primordial com a instrument, ja que, en certa manera, la matemàtica és el gran organitzador cultural que la societat d'avui en dia utilitza àmpliament $\mathrm{i}$ profundament. Les aplicacions de la matemàtica afecten pràcticament tots els camps del coneixement (les matemàtiques escolars són necessàries per a aprendre altres matèries i per a continuar aprenent matemàtiques); es troben darrere tant de les tecnologies antigues com de les modernes, i la seva utilització afecta la mateixa organització de la societat.

La visió de la matemàtica com a "activitat" i no únicament com a "sabers acabats" ens fa parar l'atenció en els processos de pensament, en les maneres d'aïllar, simbolitzar, relacionar, abstreure, explicar... Són habilitats que tenen a veure amb el desenvolupament intel-lectual de les persones, i és per això que "fer matemàtiques" per als alumnes ha de representar tenir l'oportunitat de posar en pràctica aquestes habilitats, 


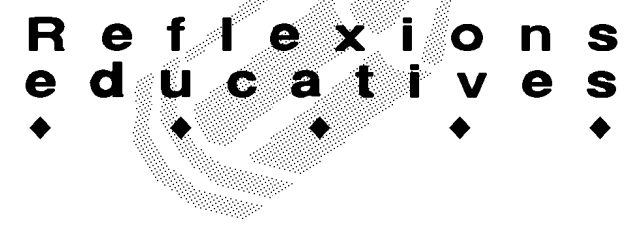

alhora que van adquirint els sabers -els conceptes, els procediments, la simbologia- que s'han revelat útils a través dels segles i que avui formen part del cos de coneixements de la disciplina matemàtica.

D'altra banda, no s'ha d'oblidar l'objectiu general perseguit per l'educació en el sentit d'ajudar les joves generacions a adaptar-se al medi en què els tocarà viure. Cal acceptar que aquest medi -una societat tecnològicament avançada com la nostra- és un medi complex i contínuament canviant. Caldrà ajustar l'acció educativa a les necessitats futures de les joves generacions i als instruments (els mediadors culturals) que la societat utilitzi en cada moment (qui es recorda d'escriure a màquina? Qui fa càlculs llargs sense emprar una calculadora?).

\section{La pràctica docent i l'assoliment de la competència}

La matemàtica escolar serà un àmbit privilegiat d'ajuda al desenvolupament competencial dels alumnes si al perseguir l'adquisició dels sabers essencials de la disciplina es treballa d'una determinada manera.

L'informe Cokcroft (1985), realitzat a Anglaterra amb l'objectiu d'orientar els currículums de matemàtica, valora extensament la matemàtica com a eina de comunicació i justifica el seu lloc a l'ensenyament obligatori pel paper instrumental que li toca jugar. Però dubta del paper

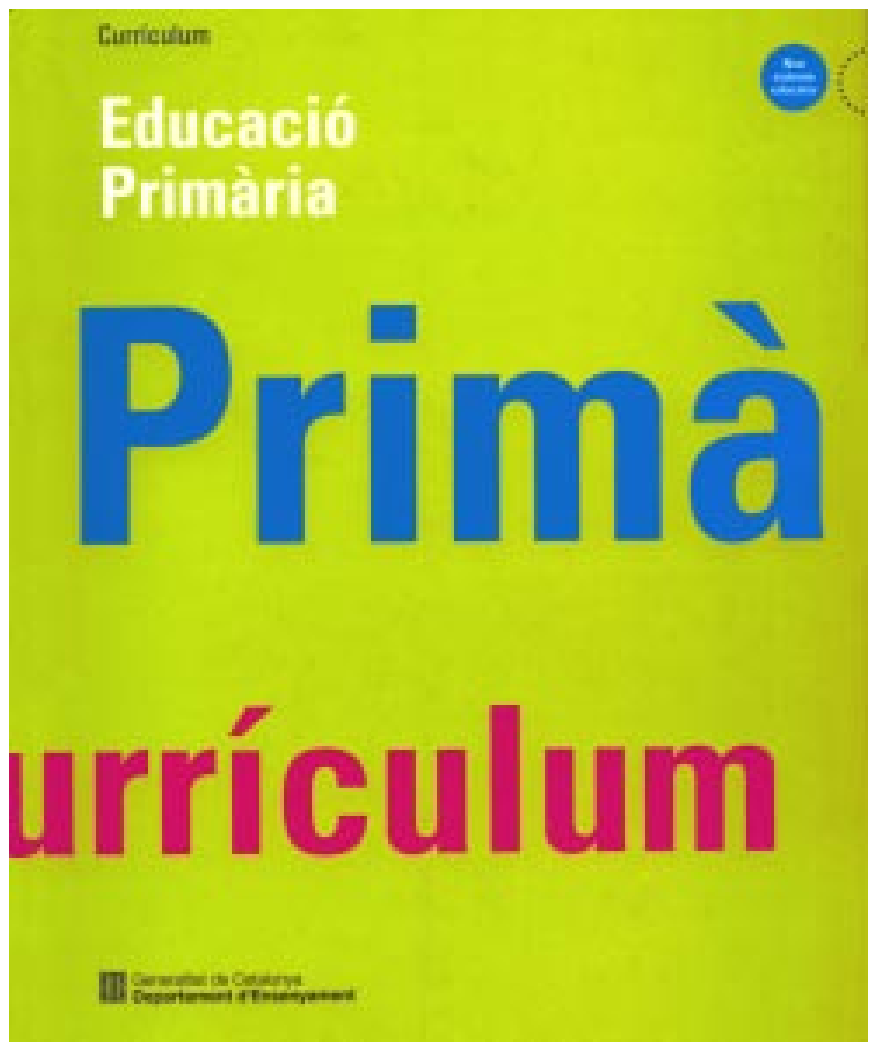

"formatiu" que es pregona a molts currículums i que bastants no compleixen, perquè depèn de com siguin treballats, o el que és el mateix, de les intencions de la pràctica didàctica. Uns continguts treballats de manera rutinària, amb poca iniciativa -0 gens- per part de l'alumne i que es mesuraran en una prova escrita a l'acabar el trimestre, poques oportunitats donen per desenvolupar habilitats intel-lectuals potents que vagin més enllà del procés de memorització i siguin útils més enllà de la pràctica escolar tradicional.

La pràctica didàctica feta amb la intenció de desenvolupar competències serà, doncs, una pràctica exigent. Exigent de cara a l'alumne perquè s'ha d'implicar en l'aprenentatge, ha d'adquirir autonomia, ha de fer ús d'habilitats diferents, etc. També serà exigent de cara al professor, ja que necessita adaptar materials comercials, cercar situacions properes a l'ambient dels seus alumnes i gestionar la diversitat de ritmes d'aprenentatge dels seus alumnes.

El currículum actualment vigent a Catalunya marca uns objectius -pel que fa al treball de l'àrea de matemàtiques- assumibles des d'una orientació competencial. Val a dir que els principis d'aprenentatge significatiu i funcional que s'hi descriu són al centre del que vol dir ser competent. L'acció didàctica sempre està emmarcada per la perspectiva psicològica que s'utilitzi per descriure com es produeix l'aprenentage. El treball de matemàtiques a l'escola sempre s'ha enfocat des d'un cert eclecticisme, ja que, principalment en els primers nivells de l'educació primària, hi ha una sèrie de sabers necessaris (noms, signes, convenis...) que corresponen més a un tipus de coneixement convencional que a un coneixement lògicomatemàtic, en el sentit que l'anomenava Piaget. Per tant, aquests sabers de tipus convencional l'alumne els aprèn com a fets, amb el que això suposa de càrrega memorística.

Però, tot i que no seria realista parlar de la matemàtica escolar sense assenyalar l'aspecte anteriorment explicat, cal dir que qüestions d'aquesta mena són realment mínimes si es comparen amb la gran quantitat d'aprenentatges que necessita aquesta disciplina. Aprenentatges que van des de les habilitats bàsiques -com relacionar, comparar, abstreure, ordenar, representar, conjecturar, provar...- fins a un seguit de conceptes interrelacionats, com són els nombres i les operacions, passant per una sèrie de procediments que tenen una base conceptual, com és el treball de la mesura o el del càlcul, per citar-ne algun exemple. En definitiva, uns aprenentatges que l'alumne ha d'adquirir de manera comprensiva i funcional.

Si l'alumne comprèn allò que manipula (físicament o mentalment), li veu una finalitat i va assolint èxits en la 


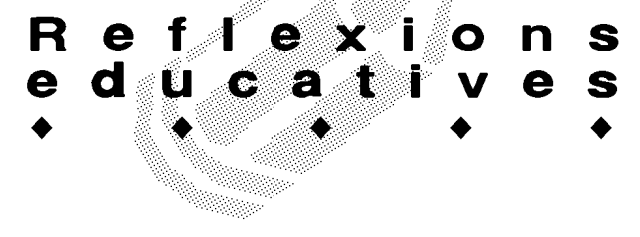

resolució de les qüestions que li posem al davant, segurament tindrà una actitud favorable vers el treball de l'àrea. La no-comprensió, la mecanització excessiva i la manca d'iniciativa per part de l'alumne, ja fa temps que se sap que generen actituds desfavorables.

Una pràctica educativa que persegueixi la competència és una pràctica d'orientació constructivista; estarà afavorida per situacions que representin reptes per als alumnes, situacions que els convidin a posar en qüestió els sabers actuals, que els obliguin a establir altres connexions, a canviar de punt de vista, a contrastar el seu parer amb els dels companys i amb els de l'adult, etc. L'alumne és l'artesà que ha de construir els seus esquemes explicatius i funcionals per continuar aprenent, per comprendre el món en què viu, per construir la seva identitat personal i per interaccionar en situacions variades. Tot això és el que es diu en les orientacions amb enfocament constructivista. Els continguts de matemàtiques són alhora objectiu i mitjà d'aquest desenvolupament intel-lectual.

Reflexionem fent servir un cas concret. Una competència bàsica a assolir en l'etapa d'educació primària és la utilització comprensiva dels nombres i les operacions, formulada en el preàmbul de les proves de competències bàsiques com: "Aplicar el coneixement del sistema de numeració decimal i de les operacions per comparar, relacionar nombres i operar amb rapidesa, buscant segons la situació un resultat exacte o aproximat”.

Comprendre com s'utilitzen els nombres, entendre quina informació ens donen, valorar si té sentit o no aquella informació, requerirà treballar situacions de la realitat de l'alumne en què apareixen quantitats i en les quals ell pugui emetre judicis. Requerirà reconèixer altres usos del nombre i la seva simbolització. Els nombres naturals no els fem servir només per expressar la cardinalitat d'una col-lecció, també hi són quan numerem les prestatgeries de l'armari on es guarda el material, als calendaris hi són per ajudar a orientar-nos temporalment, hi són quan donen nom a la sala on hi ha la classe dels alumnes o a la porta del nostre habitatge... Els alumnes que donin sentit als nombres en el seu espai social de vivència estaran capacitats per utilitzar-los.

Això que s'està explicant és com fer una crida a l'aplicabilitat, a donar sentit a les accions físiques o intel-lectuals que són pràctiques habituals, i anar des d'aquestes al coneixement abstracte de la matemàtica. A mesura que l'alumne creix en experiència i en capacitat lògica, també pot reflexionar sobre els mateixos nombres entesos com a objectes (com es relacionen, per què s'escriuen amb dues, tres... xifres, etc.) i aquestes idees, un cop assolides, serviran per construir-ne altres més potents a partir d'elles (primer només saben comptar, després ja sumen i més tard multipliquen, més tard operen amb potències i després vindrà el llenguatge algebraic...) Cada pas de matematització vertical (aquest caminar en sentit ascendent de complexitat per la pròpia disciplina) va acompanyat per moltes siuacions pràctiques que es resolen amb aquestes idees (matematització horitzontal) i que són les que donen sentit als nous aprenentatges i en justifiquen la necessitat. Els dos aspectes són imprescindibles si es vol assolir competència.

\section{El càlcul bàsic}

Especial interès mereix l'aprenentatge del càlcul a l'educació primària. A la competència de l'exemple anterior es parla "d'operar amb rapidesa". És clar que calcular amb seguretat i fluïdesa és un objectiu indefugible del currículum d'aquesta etapa. Però aquesta seguretat, fluïdesa i també flexibilitat sorgirà com a conseqüència d'un aprenentatge comprensiu del funcionament del sistema numèric i de les operacions. Un aprenentatge que busqui la comprensió exigeix la capacitat de relacionar, de verbalitzar les relacions que s'hi observin, de memoritzar algunes dades i d'aprendre a deduir-ne altres a partir d'aquestes (Per exemple, si sabem que cinc i cinc fan deu -ho veiem cada dia a les nostres mans- es pot deduir que cinc i sis són onze, o que quatre i cinc són nou).

Si davant d'un càlcul els alumnes han adquirit l'hàbit de fer una estimació del resultat, de pensar quina estratègia els seria més fàcil... es pot dir que anem pel bon camí per assolir la competència numèrica. Si el alumnes es posen a calcular aplicant una mecànica incomprensible, desesperadament i sense poder controlar ells mateixos els possibles errors comesos, és possible que haguem perdut el nord.

La necessitat d'una pràctica que agiliti els processos de càlcul pot estar recolzada en jocs diversos; tant en els jocs de taula tradicionals (que són d'ús quotidià i, per tant, propers als nens) com en jocs i activitats en suport informàtic. L'aprenentatge de les matemàtiques amb l'ajut de les possibilitats que ofereix l'ordinador és una finestra oberta que cal explorar. No és només una qüestió de canvi de format o de presentació. La qüestió rau en el fet que la nova tecnologia permet dissenyar activitats més ajustades als objectius perseguits. L'accés i l'ús generalitzat del càlcul electrònic obliga que els nous currículums donin orientacions clares en relació amb el càlcul. Avui en dia, o es calcula mentalment o es fa amb la calculadora. Cal, amb urgència, respondre preguntes com: Quin paper hem d'assignar als algorismes? Fins a quin punt els algorismes han d'estar mecanitzats? Quins criteris han d'emprar els alumnes per decidir si un càlcul es fa mijançant l'algorisme o amb la calculadora?

A França s'acaba d'estrenar una reforma curricular 


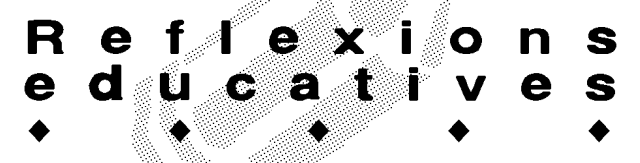

que planteja el treball de càlcul a primària, integrant el càlcul mental, els algorismes i l'ús de la calculadora, tot donant pautes clares per a cada cicle (www. eduscol. education.fr). A títol de reflexió, només s'indicarà que s'hi diu: "l'algorisme de la divisió, tal com el fem aquí (sense escriure la resta) no és objectiu ni del currículum de l'escola primària, ni del collège"però sí que és un objectiu l'estimació del nombre de xifres del quocient i la resolució de divisions mitjançant el càlcul pensat.

\section{Una reflexió per al futur: Sabers i processos}

Un cop hem arribat fins aquí, ens podem preguntar: El nou currículum podria descriure, a banda dels sabers essencials i continguts tradicionals, els processos propis de l'activitat matemàtica, amb el nom de competències, processos... o amb el que es consideri més adient? La resposta és clarament afirmativa i fins i tot gosem indicar per on podria anar el plantejament. Voldríem que el lector o lectora consideri, a partir d'ara, aquesta proposta com un "document de treball"; es tracta d'anar reflexionant sobre el tema, no de fer propostes tancades, sinó que el que pretén és aportar idees per al diàleg.

L'àmplia bibliografia existent al voltant de l'educació matemàtica ens dóna pistes de com organitzar i portar a terme un currículum realista. Realista en el sentit que sigui assumible pel qui aprèn i sigui realitzable didàcticament. Aquest currículum hauria de contemplar, d'una banda, els sabers propis de la disciplina, tradicionalment agrupats en els blocs: nombres i operacions, geometria, mesura i el tractament de la informació; blocs que han d'estar ben delimitats i seqüenciats al llarg de l'etapa. I de l'altra, explicitar les exigències del desevolupament competencial o de processos.

Per a aquest segon aspecte -el d'explicitar les exigències del desevolupament competencial-es posarà un exemple postulant, com es fa en alguns països, tres grans blocs competencials (que siguin tres, pensem que és una qüestió d'equilibri entre la descripció dels processos i que sigui didàcticament assumible) que el treball de matemàtiques requereixen, i conseqüentment, ajuden a desenvolupar. Es tractarà de caracteritzar-los amb l'ajuda del que avui en dia i a tot el món es considera una bona referència per al treball de matemàtiques a les escoles: Els principis i estàndards per a l'educació matemàtica de l'any 2000, elaborats per la Societat Americana de Professors de Matemàtiques (NCTM, National Council Teachers of Mathematics. www. nctm.org), que tenen en compte totes les investigacions recents en educació matemàtica.

\section{Processos o competències matemàtiques a desen- volupar}

Raonament de caire matematic.

L'alumne ha de ser capaç de fer raonaments de caire matemàtic per consolidar el mateix pensament $\mathrm{i}$ continuar aprenent. Raonar matemàticament consisteix a establir relacions, combinar-les entre elles i sotmetre-les a diverses operacions per crear nous conceptes $\mathrm{i}$

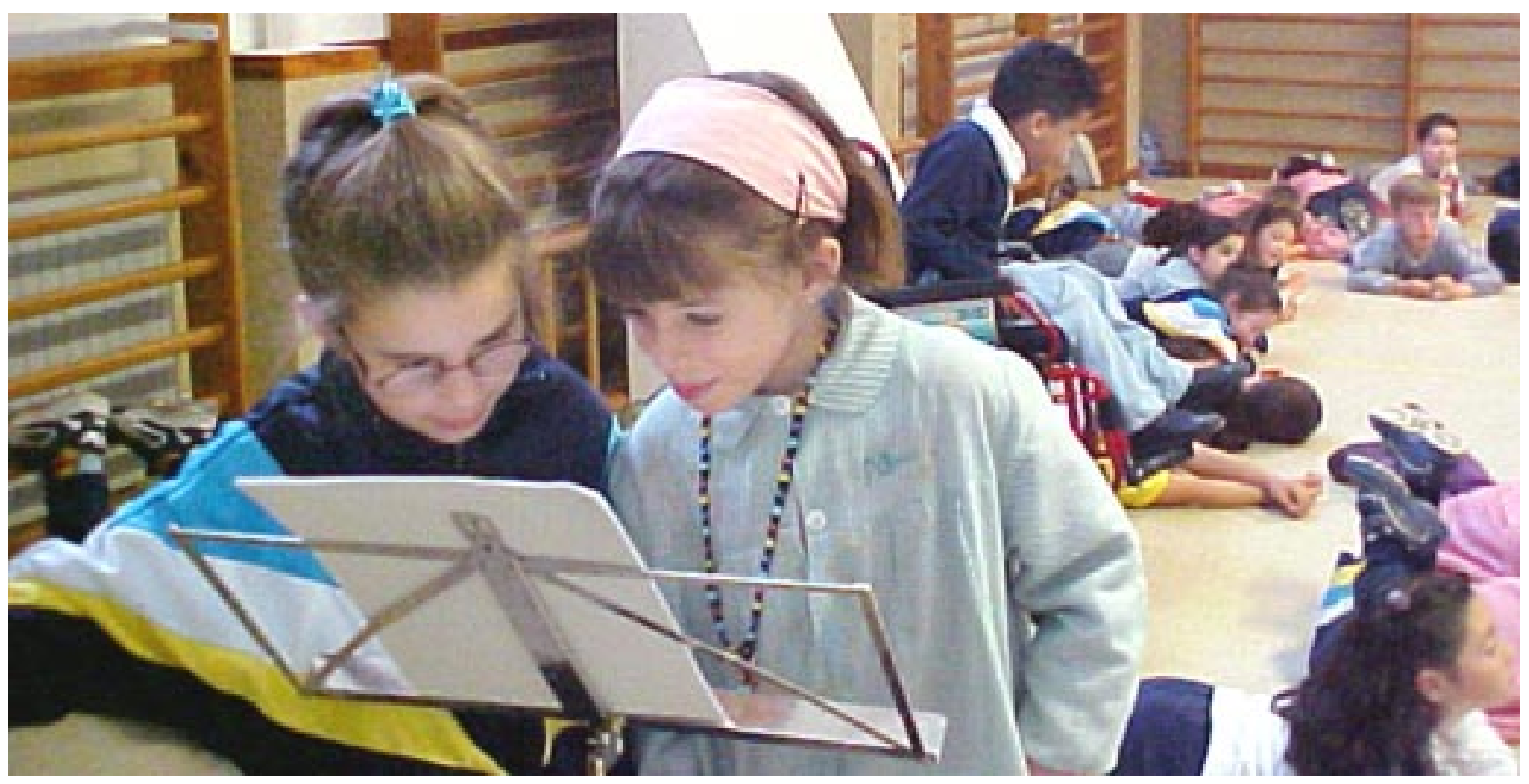




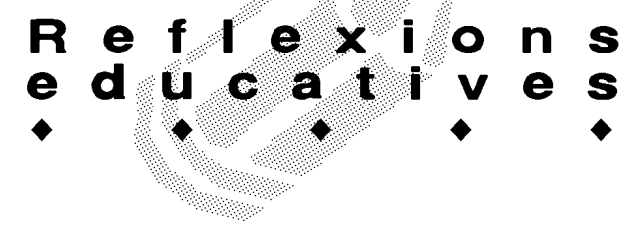

progressar en l'exercici del pensament matemàtic.

El raonament matemàtic que s'ha de desenvolupar a l'escola primària és deductiu, inductiu i creatiu alhora. És deductiu en la mesura que l'alumne ha d'aprendre a obtenir una conclusió a partir de les dades d'una situació problema. És inductiu en la mesura que els demanem la recerca de regles o lleis a partir d'un conjunt d'observacions. I és creatiu perquè l'alumne ha d'imaginar-se combinacions d'operacions per trobar diverses respostes a una situació problema.

En els estàndards curriculars es diu que els alumnes haurien de ser capaços de: reconèixer $i$ usar relacions entre idees matemàtiques; entendre com es connecten unes idees matemàtiques amb les altres; fer conjectures i tractar d'investigar per saber si és cert o fals; desenvolupar arguments per defensar el propi punt de vista; i usar diferents tipus de raonament: inducció, deducció, analogia...

\section{Resolució de problemes.}

Resoldre problemes s'ha d'entendre en sentit clàssic, com el procés que permet, a partir d'unes informacions conegudes, arribar a inferir-ne d'altres que es demanen. Per fer això, l'alumne ha de mobilitzar totes les eines que tingui al seu abast i ha d'aprendre a fer-ho. Però resoldre problemes també s'ha de veure com una modalitat didàctica; els nous aprenentatges es produeixen si els mateixos alumnes s'impliquen en la recerca de respostes.

En aquest sentit i seguint els estàndards, els alumnes haurien de ser capaços de: construir nous coneixements a partir de resoldre problemes; resoldre problemes de contextos quotidians i de context matemàtic; aplicar i adaptar estratègies diferents a la resolució de problemes; adquirir confiança en les seves possibilitats i gaudir amb el treball matemàtic; i ser conscients de les seves maneres de pensar, i entendre i valorar les dels altres.

Representació i comunicació.

Actualment la matemàtica es valora molt quan s'entén com a llenguatge clar i precís per rebre i donar informació. Aprendre a utilitzar aquest llenguatge significa ser capaç de produir i entendre representacions diferents. Un simple esquema figuratiu que descriu la transformació en un problema elemental d'aritmètica; una expressió numèrica que descriu la mateixa situació; un gràfic de barres que indica els hàbits alimentaris dels alumnes de la classe; una línia poligonal que representa trams, punts de referència i girs que descriuen el camí de casa a l'escola; una taula de doble entrada on llegim la informació d'un horari de trens... i el llenguatge verbal, vehicle fonamental en la comunicació, i que també requerirà el coneixement de termes propis i la seva utilització en situacions pertinents. Aquests són Ilen- guatges bàsics en la societat d'avui en dia, però també són necessaris en el mateix procés d'aprenentatge.

Desenvolupar capacitats de representació i comunicació per aprendre i per comunicar-se de manera efectiva, s'aconseguirà si els alumnes són capaços de: crear i usar diferents representacions per organitzar, recordar i comunicar idees matemàtiques; utilitzar diferents representacions (figuratives, simbòliques, verbals) i passar d'unes a les altres per comunicar-se o resoldre problemes; usar representacions i models per interpretar fenòmens del món físic, del món social o de la mateixa matemàtica; organitzar i consolidar el seu pensament matemàtic a través de la comunicació; comunicar el seu pensament de manera clara i concisa al seus companys, als mestres i als altres adults; i analitzar i avaluar el pensament $i$ les estratègies dels altres.

Aquests tres blocs s'han de desenvolupar alhora que es treballen els continguts de matemàtiques, agrupats en els quatre blocs conceptuals abans citats. Com es veu, apunten a una "manera de fer" i no es pot pensar que es poden treballar cada un de manera separada, sinó que, aquesta distinció dels tres aspectes ha d'ajudar els mestres a entendre què hi ha al darrere de "fer" $\mathrm{i}$ "aprendre matemàtiques". És evident que per fer raonaments de caire matemàtic necessitem els conceptes, les representacions i comunicar-nos amb d'altres o amb nosaltres mateixos. I el marc natural per fer raonaments matemàtics és la tasca de resoldre problemes. El currículum d'Anglaterra (www.nc.uk.net) i el del Québec (www.meq.gouv.qc.ca) són exemples actuals d'aquests plantejaments.

La consideració d'aquests processos i els sabers essencials de la disciplina per tractar les quantitats, les magnituds, referir-se a l'espai, organitzar i codificar informació, que són fenòmens a l'abast dels alumnes de primària, ha d'ajudar a aconseguir que s'interessin per aquesta àrea $\mathrm{i}$ que desenvolupin actituds favorables vers el seu aprenentatge. Com bé sabem els professors i les professores, i també s'indica en algunes anàlisis (Linares, 2003), és un objectiu indefugible per assolir competència.

\section{Referències bibliogràfiques}

CROKCROFT, W.M. Las Matemáticas sí cuentan. Ed. Labor-MEC. Madrid. 1985.

LINARES, S. Matemáticas escolares y competencia matemàtica. A Didàctica de les Matemàtiques. Ed. Pearson. Prentice Hall. 2003.

GIRONDO, L. La competència per ser ciutadà del segle XXI i la contribució de l'escola a la seva adquisició. "Comunicació Educativa», 17 (2004) 4-5. 